\title{
Research Square \\ Valorization of Pet-Al Composite Obtained From Packaging Waste in Basic Conditions
}

Aymen Souilhi ( $\square$ aymen.souilhi1@gmail.com )

University of Carthage

\section{Rym Abidi}

University of Carthage

\section{Research Article}

Keywords: Separation, Packaging wastes, Basic, Recycle

Posted Date: December 30th, 2020

DOl: https://doi.org/10.21203/rs.3.rs-131828/v1

License: (c) (1) This work is licensed under a Creative Commons Attribution 4.0 International License. Read Full License 


\title{
Valorization of Pet-Al composite obtained from packaging waste in basic conditions
}

Aymen Souilhi ${ }^{1}$, Rym Abidi $^{1}$

${ }^{1}$ Laboratory for the Application of Chemistry to Natural Resources and Substances and to the Environment (LACReSN). University of Carthage, Faculty of Sciences of Bizerte, 7021 jarzouna, Tunisia.

The corresponding Author: Aymen Souilhi

Rue allyssa $\mathrm{N}^{\circ} 9$ Menzel Bourguiba 7050, Tunisia

Email : aymen.souilhi1@ gmail.com

GSM : 0021696472004

\begin{abstract}
The recycling of Risidu Pet-Al (a laminated foil made from polyethylene and aluminum foil in food brike packaging) continues to be a challenge. Despite the fact that previous studies proposed green solutions for the recycling of the Pet-Al composite, the handicaps linked to the increase of the cost of the reagents involved in the recycling mechanism, the complexity of the steps, resulting in products with a critical aspect, really reflect a problem. The growing concern about environmental impacts such as greenhouse gas emissions from inceneration treatment is distinctly clear to the scientific community. This article involves chemical treatment by adding a strong base $\mathrm{NaOH}$ or $\mathrm{KOH}$ as the dissolving reagent, Followed by the addition of the strong acid $\mathrm{HCl}$. The birth of a neutral environment promotes the recovery of aluminum salts as well as sodium (or potassium). The released $\mathrm{H}_{2}$, polyethylene and cardboard are also products regenerated by this recycling.
\end{abstract}


The study contributes to the optimal conditions of time concentration temperature as well as the mode of separation. The recovered salts are identified, however their purity remains an important factor of quality before adapting their use.

Keywords: Separation ; Packaging wastes ; Basic ; Recycle.

\section{Introduction}

Aseptic composite packaging materials are mainly composed of paper, aluminum and low density polyethylene (LDP) plastics; a small amount of printing ink and adhesives also present. Food brick packaging generally contains $73 \%$ fiber, $25 \%$ LDP, $5 \%$ aluminum and $2 \%$ others [1]. The aluminum-plastic laminates of the packaging structure are formed by a highfrequency and hot pressing process, which tightly bonds layers of aluminum and LDP plastic. The aluminum-plastic composite is difficult to be separated or broken down effectively into elementary components. The most effective approach to convert this waste into precious material is currently to separate the laminated packaging composites into several simple materials containing fibers, aluminum and plastics [2-4]. Speaking on the sustainability and non-ferrous metal resources, the separation and reuse of materials has a high regenerated value. The fibers can be extracted from these post-consumer aseptic packaging by hydraulic dissociation. Reinforced aluminum-plastic laminates can be separated by various recycling approaches and separation with solvents has attracted the attention of many researchers. Supercritical water, inorganic acid and organic solvents such as hydrochloric acid, nitric acid, formic acid, acetic acid, unique components such as benzene and acetone, and a mixture of solvents have been put into practice [5-8]. These solvent-based approaches are effective in separating aluminum-plastic laminates, but it creates solvent pollution. For this, our approach is to use reagents giving a neutral medium during the recovery of the products, to minimize 
impact on the environment. For that a wet recycling method; whose separation mechanism as well as the appropriate reagent and process parameters have been determined.

\section{Materials and Methods}

The Pet-Al residue is separated from the cardboard by simple pulping with distilled water at room temperature, Fig. 1(A).

In fact, the adhesive used during the manufacture of food bricks such as polyethylene-comethacrylic acid (EMAA) leads on the one hand to the increase of the viscosity and on the other hand ensures the attachment of the layers. Therefore we need to gently scrape the Pet-Al residue to remove the thin cardboard still linked to one of the two sides Fig. 1(B). The Pet-Al residue is washed then dried and cut in two dimensions : A square of $5 \mathrm{~cm} / 5 \mathrm{~cm}$ with mass $\mathrm{M}=162.5 \mathrm{mg}$ and a square of $1 \mathrm{~cm} / 1 \mathrm{~cm}$ with mass $\mathrm{M}=6.5 \mathrm{mg}$ using a Kern-type precision balance $(0.001 \mathrm{~g})$. The reagents prepared are $6 \mathrm{NaOH}$ solutions (Novachim) of $1 \mathrm{M}, 2 \mathrm{M}$, $4 \mathrm{M}, 6 \mathrm{M}, 8 \mathrm{M}$ and $10 \mathrm{M}$ concentration; the same for $6 \mathrm{KOH}$ solutions (Panreac). The temperature is measured by using a digital thermometer; the heating is done in a thermostatically controlled water bath model Stuart RE300B.

Several test groups were conducted to determine the optimal separation reagent, see the appropriate mechanism and process parameters and produce a mass review for the aluminumpolyethylene separation system. The aluminum-polyethylene composite packaging material was introduced into test tubes with the reagents in question at different concentrations ranging from $1 \mathrm{M}$ to $10 \mathrm{M}$ and at temperatures of $20{ }^{\circ} \mathrm{C}, 40{ }^{\circ} \mathrm{C}, 60{ }^{\circ} \mathrm{C}$ and $80{ }^{\circ} \mathrm{C}$. The mass concentration of aluminum in the solution of a reagent was analysed by inductively coupled plasma mass spectrometry ICP-OES model Perkin Elmer optima 8000. The microscopic structure of the Pet-Al composite samples of the packaging materials were determined by using ultra high resolution SEM field emission scanning electron microscope Thermo scientific 
Q250. We used an IR spectrometer of Perkin-elmer (FTIR SPECTRUM 1000) to record the spectra on $\mathrm{KBr}$ pellet samples. The separation results were presented in terms of separation time, and the aluminum loss report. The separation time is the moment when the layers of polyethylene and aluminum are completely separated. The aluminum loss ratio is the percentage of $\mathrm{Al}$ that has reacted, with the original $\mathrm{Al}$ reagent solution in the Pet- $\mathrm{Al}$ composite package when the separation reaction has just ended. Each test was repeated three times, the average of the closest values are taken as final measurement values.

\section{Results and discussion}

\subsection{Separation mode}

To see the action model of $\mathrm{NaOH}$ or $\mathrm{KOH}$ solution on a solid residue of polyethylenealuminum Rsd (Pet-Al), we introduce into a beaker a piece of Pet-Al of dimension $25 \mathrm{~cm}^{2}$ (a $5 \mathrm{~cm} / 5 \mathrm{~cm}$ square) with a $1 \mathrm{M}$ concentration solution at room temperature. Dissolving aluminum is not a single step, the corrosion kinetics of aluminum involves two conjugate electron transfer processes, the first between $\mathrm{Al}$ and $\mathrm{Al}^{3+}$ the second between $\mathrm{H}_{2} \mathrm{O}$ and $\mathrm{H}_{2}$. According to the bibliography the chemical reaction at basic $\mathrm{pH} \geq 12$ takes place as follows [9].

$$
2 \mathrm{Al}+6 \mathrm{H}_{2} \mathrm{O}+2 \mathrm{OH}^{-} \longrightarrow 2 \mathrm{Al}(\mathrm{OH})_{4}^{-}+3 \mathrm{H}_{2} \Delta
$$

As a result, the dissolved aluminum level will depend on several factors, including the $\mathrm{OH}^{-}$ hydroxyl concentration in solution also the presence of $\left[\mathrm{Al}(\mathrm{OH})_{4}\right]^{-}$without forgetting the temperature factor. Fig. 2 shows the aluminum layer degradation stacked between the two polyethylene layers going from the sides towards the center (centripetal degradation) observed by the action of $\mathrm{NaOH}$ or $\mathrm{KOH}$. 
To improve the reaction speed, the size of a $25 \mathrm{~cm}^{2}$ Pet- $\mathrm{Al}$ residue piece is minimized into 25 elementary pieces of $1 \mathrm{~cm}^{2}$ area and keeping the same liquid / mass ratio. Each sample is introduced into a volume equal to $10 \mathrm{~mL}$ of $1 \mathrm{M}$ of sodium hydroxide and heated to $\mathrm{T}=60{ }^{\circ} \mathrm{C}$, then their progress is monitored over time ; the results are illustrated in Table $\mathbf{1 .}$

The attack speed improved fourteen times for the 25 pieces of $1 \mathrm{~cm}^{2}$ of surface, the attack of $\mathrm{OH}^{-}$ions became more favorable along the perimeter which is called attack track $\mathrm{P}$ :

$\mathrm{P}_{\mathrm{B}}=5 \mathrm{P}_{\mathrm{A}} \quad\left(\mathrm{P}_{\mathrm{A}}\right.$ and $\mathrm{P}_{\mathrm{B}}$ are the attack tracks of samples $\mathrm{A}$ and $\mathrm{B}$ respectively $)$

We can therefore confirm that on basic medium the attack process of aluminum compiled between 2 layers of polyethylene, is totally different to that in acid medium; in fact, in the latter, the $\mathrm{H}^{+}$ions of the methanoic acid used cause cracks on the surface of the plastic and penetrate there through (very small cation) to oxidize the aluminum [10]. To ensure the attack model, we analyze the surface of a sample of Rsd (Pet-Al) by SEM, Fig. 3 present images taken at an intermediate instant before the plastic total separation from the aluminum.

The cracks observed in an acid medium on the polyethylene layer are absent in our case, which proves that the $\mathrm{OH}^{-}$anion is unable to penetrate through the polyethylene where the $\mathrm{Al}_{2} \mathrm{O}_{3}$ layer remains intact. In our case the attack is done by the edges, the attack speed improves as we minimize the sample size.

\subsection{Conditions of the separation process}

\subsubsection{Concentration of the reagent and separation temperature}

In order to see the favorable separation conditions, we study the concentration and temperature effects on the reaction kinetics, we keep the same liquid / solid ratio for each test $(10 \mathrm{ml} / 1 \mathrm{pcs}$ of $1 \mathrm{~cm}^{2}$ of Rsd (Pet-Al)). The reaction end was marked by the total dissolution of the aluminum until the plastic separation, see Fig. 4 . 
For the two separation reagents, two differents behaviors are observed depending on whether the temperature is below or above $40{ }^{\circ} \mathrm{C}$; indeed if the temperature is lower than $40{ }^{\circ} \mathrm{C}$ one expects a too long separation time. Whereas, when the temperature is higher than $40{ }^{\circ} \mathrm{C}$, the duration is much shorter. Except that, an anomaly was observed for the $10 \mathrm{M}$ concentration of the $\mathrm{NaOH}$ reagent characterized by a slower speed same that of $1 \mathrm{M}$. This anomaly may be due to a chemical reaction dynamics blockage caused by the aluminum complexation with $\mathrm{OH}^{-}$in $\mathrm{NaOH}$ solution when concentration values exceed $8 \mathrm{M}$, also the $\mathrm{OH}^{-}$ions consumption and their generations must be taken into account [11]. We can conclude that the temperature $60{ }^{\circ} \mathrm{C}$ and the concentration $4 \mathrm{M}$ are the most adequate kinetic parameters for the separation, except that, for the reagent $\mathrm{NaOH}$ the separation time is slightly less than that of $\mathrm{KOH}$.

\subsubsection{The liquid-solid ratio}

At a basic solutions volumes ranging from 3 to $7 \mathrm{ml}$ of $4 \mathrm{M}$ concentration, $100 \mathrm{mg}$ of Rd (Pet$\mathrm{Al}$ ) are introduced, a temperature equal to $60{ }^{\circ} \mathrm{C}$ was carried out, the results by ICP-OES are shown in Fig. 5.

The quantity of aluminum decreases strongly for $\mathrm{KOH}$ when the volume increase, on the other hand it remains almost constant for $\mathrm{NaOH}$. The activation energy at this temperature is greater in the presence of $\mathrm{KOH}$, this is confirmed by (Sloter) [12] but without any explanation for such chemical behavior. The activation energy of corrosion is related to the exchange current density $\mathrm{i}_{0}$ : the greater the activation energy, the lower $\mathrm{i}_{0}$ so that corrosion progresses more slowly, and vice versa [13]. So the increase in volume for $\mathrm{KOH}$ directly affects the corrosion current $i_{0}$ hence the decrease of generated aluminum amount. It can be concluded that the $\mathrm{NaOH}$ reagent is best suited for separation under these conditions of temperature and concentration, with a liquid-solid ratio equal to $30 \mathrm{~L} / \mathrm{kg}$ of Rsd (Pet-Al). 


\subsection{Treatment of the residual basic solution}

In order to minimize the impact on the environment, also restore the aluminum which exists in the form of $\left[\mathrm{Al}(\mathrm{OH})_{4}\right]^{-}$in the strongly basic solution, an acid treatment is used by adding $1 \mathrm{M}$ $\mathrm{HCl}$ solution (SIGMA-ALDRICH 37\%) until a neutral pH solution we obtained two phases, Fig. 6 show a white phase and a second transparent phase above the first.

Indeed, the free $\mathrm{OH}^{-}$in the solution ( $\mathrm{NaOH}$ reagent initially introduced) are in excess compared to the hydroxides forming $\mathrm{NaAl}(\mathrm{OH})_{4}$, so free $\mathrm{OH}^{-}$are dosed first according to reaction (eq2), which causes the drop in $\mathrm{pH}$. For $\mathrm{pH}<11$ a white precipitate begins to appear, at this moment we are witnessing at the dosage of the $\mathrm{OH}^{-}$linked to pass to the form of aluminum hydroxide $\mathrm{Al}(\mathrm{OH})_{3}$ according to reaction (eq3).

$\mathrm{HCl}+\mathrm{NaOH} \rightarrow \mathrm{NaCl}+\mathrm{H}_{2} \mathrm{O} \quad($ eq2)

$\mathrm{NaAl}(\mathrm{OH})_{4}+\mathrm{HCl} \rightarrow \mathrm{NaCl}+\mathrm{H}_{2} \mathrm{O}+\mathrm{Al}(\mathrm{OH})_{3}$

The sum of the chemical equations (eq2) and (eq3) give:

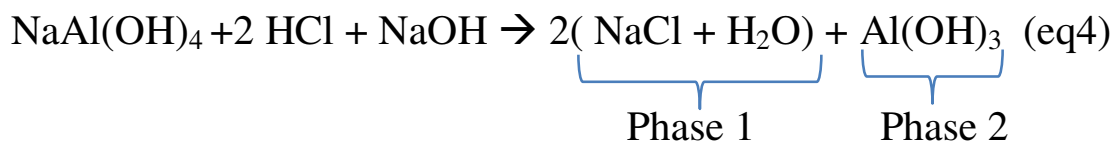

The two phases 1 and 2 are then separated, filtered under vacuum and then heated to a temperature above $100{ }^{\circ} \mathrm{C}$, after drying, two solid products SD2 from phase 1 and SD3 from phase 2 with different appearance are obtained.

\subsubsection{SEM Analysis of the solids SD2 and SD3}

The solid SD2 SEM analysis in Fig. 7, shows a crystalline appearance which appears sharper for an enlargement of $50 \mu \mathrm{m}$.

The SEM spectrum is given in Fig. 8, the appearance of two intense lines characteristic of sodium and chlorine confirms the presence of the sodium chloride salt. 
According to Table 2, chlorine and sodium present approximately the same atomic percentage which gives $\mathrm{x}=\mathrm{y}=1$ for the crude formula $\mathrm{Na}_{\mathrm{x}} \mathrm{Cl}_{\mathrm{y}}$, the elements which appear such as $\mathrm{C}$ and O which may have originated from (EMAA) are considered as impurities.

The solid SD3 SEM analysis (white precipitate) in Fig. 9 shows an aspect seems like aluminum hydroxide.

The SEM spectrum of the solid SD3 in Fig. 10 shows two intense lines for aluminum and oxygen which proves the formation of a white precipitate of aluminum hydroxide.

According to Table 3, the atomic percentage for a compound of crude formula $\mathrm{Al}_{\mathbf{z}} \mathrm{O}_{\mathbf{t}}$ gives $\mathrm{t} / \mathrm{z}=3.9 \sim 4$.

\subsubsection{Infrared analysis of SD2 and SD3}

The rehydration experiments of amorphous aluminum oxides carried out by Verdes.G (1987), showed that the phase which formed in weakly basic medium at $25^{\circ} \mathrm{C}$ is Bayerite, these experiments also show the considerable influence of the solid surface adsorption phenomena. Boehmite can sometimes precipitate at the same time as bayerite and gibbsite probably in small pores where certain water molecules are strongly linked to the surface of the solid [14]. Studies carried out in the laboratory have made it possible to demonstrate the absorption intensity component located at approximately $3460 \mathrm{~cm}^{-1}$ on the infrared spectrum in transmission of pellets of gibbsite diluted in $\mathrm{KBr}$ [15-17]. The infrared spectra of the solid SD2 and SD3 are respectively presented in Fig. 11 and Fig. 12, the spectral identification is deduced by comparison with the references data, the results are grouped in Table 4.

The SD2 solid presents a broad band of non-binding $\mathrm{OH}$ and $\mathrm{OH}$ linked to the aluminum hydroxide which is already detected by SEM in a trace form, the deformation vibrations which appear for the two solids are due to the carbon-oxygen bonds. single and double type of 
EMAA, except that for SD3 solid the band $976 \mathrm{~cm}^{-1}$ corresponds to the Al-OH signal of gibbsite [20]; for SD3 solid it appears in the form of mixtures of Bayerite and Gibbsite in proportions not yet identified.

\subsection{Development of a continuous separation system}

The adequate conditions already concluded are applied to a mass $\mathrm{m}=1 \mathrm{~kg}$ of post-consumed food bricks : The solid liquid ratio was equal to $30 \mathrm{~L} / \mathrm{Kg}$, the $\mathrm{NaOH}$ concentration equal to $4 \mathrm{M}$ and the temperature $\mathrm{T}$ equal to $60^{\circ} \mathrm{C}$. The certainty of the results during the passage from the micro-mass scale (samples: $\mathrm{m}_{1}=35.1 \mathrm{mg}, \mathrm{m}_{2}=5.4 \mathrm{~g}$ ) of FB (Food bricks) to the macromass scale (samples: $\mathrm{m}_{3}=100 \mathrm{~g}, \mathrm{~m}_{4}=1 \mathrm{Kg}$ ), has been verified by following the deduced mass percentages relating to the carton, plastic, solid aluminum, $\mathrm{RSD}(\mathrm{Pet}-\mathrm{Al})$ and released hydrogen; as for sodium hydroxide and aluminum hydroxide they are excluded because they require the addition of hydrochloric acid to be formed. Fig. 13 shows an acceptable similarity when switching from sample $\mathrm{m}_{1}$ to $\mathrm{m}_{4}$, except that the mass loss, having a low value equal to $0.17 \%$ relative to sample $m_{1}$, does not appear in this figure.

The extrapolation of the study for $\mathrm{m}=1$ tonne of food bricks is illustrated in Table $\mathbf{5}$. Note that the mass loss per tonne of food brick is equal to $6.28 \%$.

\subsubsection{Process flow}

The results of this study are used for the design of an industrial continuous separation process, which is formed by three units U1, U2 and U3 as shown in Fig. 14 .

The food bricks are crushed in a pulper in the presence of water, the paper pulp separated from the RSD (Pet-Al) passes with the water in U3 provided with a filtration thus separating the water from the paper pulp. RSD (Pet-Al) passes through a stainless steel reactor, under the action of sodium hydroxide, hydrogen is released which is then stored at room temperature and 
at a pressure equal to 700 bar. A second filtration separates the PBD from the filtrate, that under the action of hydrochloric acid and via decantation followed by filtration we manage to extract the aluminum hydroxide (Gel) which is transformed with lyophilization into aluminum hydroxide $(\mathrm{Sd})$. The new resulting filtrate is distilled to give sodium chloride ( $\mathrm{Sd})$. The water resulting from the distillation will be used for washing the LDP, and will eventually be recycled before being introduced into a new cycle.

\subsubsection{Control system}

The control of temperature, pressure, volume, mass and $\mathrm{pH}$ is necessary throughout the recycling process especially with regard to the inputs as also for the steps listed in Table 6.

\subsubsection{Economic benefits}

The limited choice of calculation of the benefits relating to the treatment of 1 ton of FB., is based only on two factors: The purchase prices of the raw material and the sale prices of the recovered products. The unit prices used are the average of three prices existing on the world market in March 2020. According to Table 7, a profit of 244.58 \$ per tonne is deducted. If added value is introduced to the recovered products, the profit concluded will have significant growth.

\section{Conclusion}

In conclusion, the closed cycle chemical recycling process proposed by this study ensures a neutral acid-base environment during the recovery of the major products, which constitutes an advantage on an industrial and environmental scale. So the results obtained give a relatively large favor for the reagent $\mathrm{NaOH}$ in front of $\mathrm{KOH}$. That is to say, the mechanism involved in the separation of aluminum and polyethylene, already confirmed by SEM, is the attack of the reagent only from the edges. The appropriate parameters for the separation of aluminum and 
polyethylene are concluded. Second, by acid treatment of the residual solution, two products are recovered which are a sodium chloride salt (or potassium chloride if the starting reagent is $\mathrm{KOH})$ and aluminum in different possible forms of hydroxide, these two products remain to be furthermore purified. Their applications being important in various fields such as laboratories, water treatment and pharmaceuticals.

\section{Acknowledgments}

I warmly thank Pr. Rym Abidi for hosting me in his lab and to all the technicians of the faculty of science of Bizerte, without forgetting Pr Kmar Trabelsi for the linguistic revision of english.

\section{References}

[1] : Gordon, L., 1996. The environmental profile of tetra pack aseptic cartons. China Packag. 16, 29-31 (in Chinese with English abstract).

[2] : Martínez-López, M., Martínez-Barrera, G., Barrera-Díaz, C., Ureña-Núñez, F., Reis, J.M.L. Dos, 2016. Waste Tetra Pak particles from beverage containers as reinforcements in polymer mortar: Effect of gamma irradiation as an interfacial coupling factor. Constr. Build. Mater. 121, 1-8. https://doi.org/10.1016/j.conbuildmat.2016.05.153

[3] : Rodriguez-Torres, J., CalzadaAndrés-Valeri, V.C., -Perez, M.A., Rodriguez-Hernandez, J., 2018. Exploratory study of porous asphalt mixtures with additions of reclaimed tetra pak $\begin{array}{lllll}\text { material. } & \text { Constr. } & \text { Build. } & \text { Mater. } & \text { 233-239, }\end{array}$ https://doi.org/10.1016/j.conbuildmat.2017.11.067

[4] : Y1lgör, N., Kartal, S.N., Houtman, C., Terzi, E., Kantur, A., Köse, C., Piskin, S., 2012. Composite boards produced from waste Tetra Pak packaging materials: Chemical properties and biological performance. Int. Conf. Recycl. reuse. 4-6. 
[5] : Rodríguez-Gómez, J.E., Silva-Reynoso, Y.Q., Varela-Guerrero, V., Núñez-Pineda, A., Barrera-Díaz, C.E., 2015. Development of a process using waste vegetable oil for separation of aluminum and polyethylene from Tetra Pak. Fuel 149, 90-94. https://doi.org/10.1016/j.fuel.2014.09.032

[6] : Cervantes-Reyes, A., Núñez-Pineda, A., Barrera-Díaz, C., Varela-Guerrero, V., MartínezBarrera, G., Cuevas-Yañez, E., 2015. Solvent effect in the polyethylene recovery from multilayer postconsumer aseptic packaging. Waste Manag. 38, 61-64. https://doi.org/10.1016/j.wasman.2015.01.034

[7] : Zhang, S.F., Zhang, L.L., Luo, K., Sun, Z.X., Mei, X.X., 2014. Separation properties of aluminium-plastic laminates in post-consumer Tetra Pak with mixed organic solvent. Waste Manag. Res. 32, 317-322. https://doi.org/10.1177/0734242X14525823

[8] : Baskoro Lokahita, Muhammad Aziz, Yoshikawa, K., Takahashi, F., 2017. Energy and resource recovery from Tetra Pak waste using hydrothermal treatment. Appl. Energy 207, 107113. https://doi.org/10.1016/j.apenergy.2017.05.141

[9] : Mokhtar, M., Zainal, M., Talib, M., Tasirin, S.M., Majlan, E.H., 2014. Malaysia Handbook on the Emerging Trends in Scientific Research, Proceedings Book of ICETSR.

[10] : Yan, D., Peng, Z., Liu, Y., Li, L., Huang, Q., Xie, M., Wang, Q., 2015. Optimizing and developing a continuous separation system for the wet process separation of aluminum and polyethylene in aseptic composite packaging waste. Waste Manag. 35, 21-28. https://doi.org/10.1016/j.wasman.2014.10.008

[11] : Renaudin, G., 1998. I) Study of a simple aluminum hydroxide: bayerite II) Study of a family of double lamellar aluminum and calcium hydroxides: AFm phases (Aluminates Tetracalciques Hydratés). http://www.theses.fr. Nancy 1. 
[12] : Wang, C.-C., Chou, Y.-C., Yen, C.-Y., 2012. Hydrogen Generation from Aluminum and Aluminum Alloys Powder peer-review under responsibility of MRS-Taiwan. Procedia Eng. 36, 105-113. https://doi.org/10.1016/j.proeng.2012.03.017

[13] : A Brett, C.M., Maria Oliveira Brett, A., New York Tokyo, O., n.d. ELECTROCHEMISTRY Principles, Methods, and Applications.

[14] : Verdes, G., Gout, R., 1987. Rehydration of amorphous aluminum oxides. Application to the study of the Boehmite-Bayerite equilibrium. Bull. Mineral. 110, 579-587. https://doi.org/10.3406/bulmi.1987.7999

[15] : Phambu, N., 1996. Preparation of aluminum hydroxides: morphological and surface structural characterization: application to the study of an aluminum passivation layer.

[16] : Phambu, N., Humbert, B., Burneau, A., 2000. Relation between the infrared spectra and the lateral specific surface areas of gibbsite samples. Langmuir 16, 6200-6207. https://doi.org/10.1021/la000098v

[17] : Rinnert, E., characterization by vibrational microscopy and adsorption of probe molecules from reactive sites of the surface of an aluminum hydroxide, 2001 DEA chemistry and molecular physico-chemistry, Henri Poincaré University .

[18] : Saalfeld, H., Wedde, ] $\backslash 1,1974$. Refinement of the crystal structure of gibbsite, $\mathrm{AI}(\mathrm{OH})_{3}$, Bd.

[19] : Wang S. L. et Johnston C. T., Assignment of the structural OH stretching bands of gibbsite, American Mineralogist, 200, 85, 739-744. 
[20]: Marie-Camille Jodin, From taking into account morphological and structural heterogeneities towards the interpretation of the global reactivity of an aluminum hydroxide, thesis 6 dec 2004, Henri Poincaré University. 


\section{Figures}
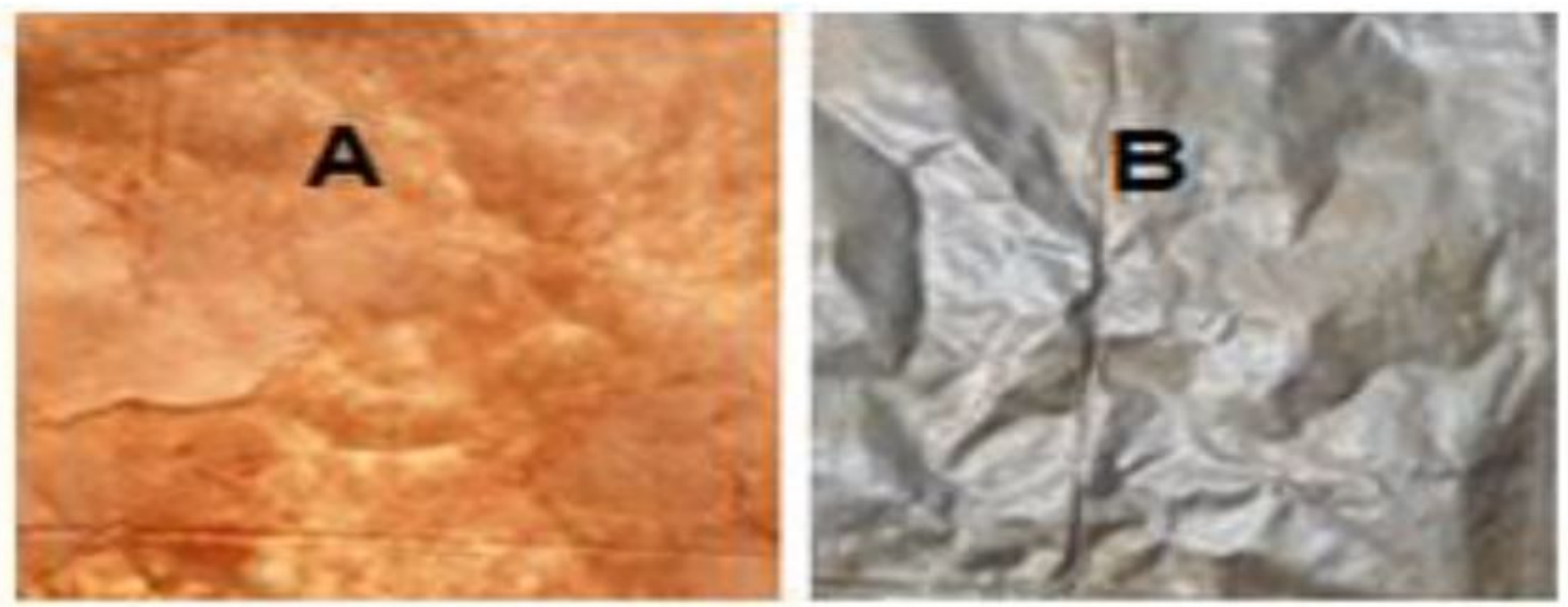

\section{Figure 1}

Pet-Al residue (A) : after pulping with distilled water, (B) : treated by scraping
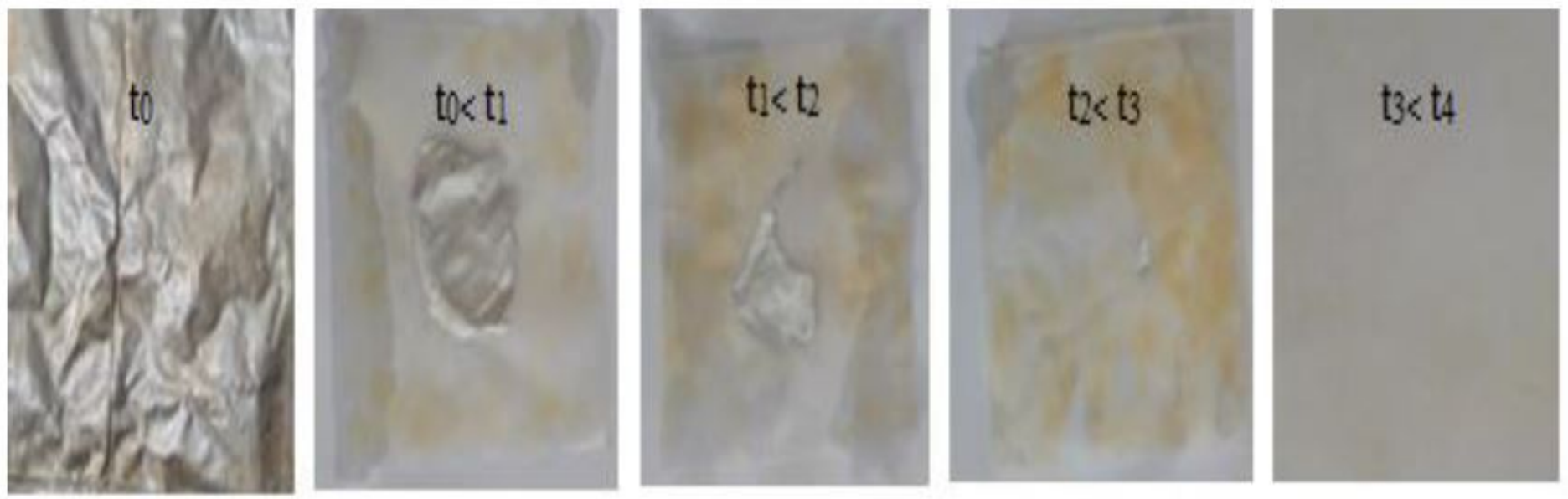

Figure 2

The aluminium layer degradation over the time $t$ 

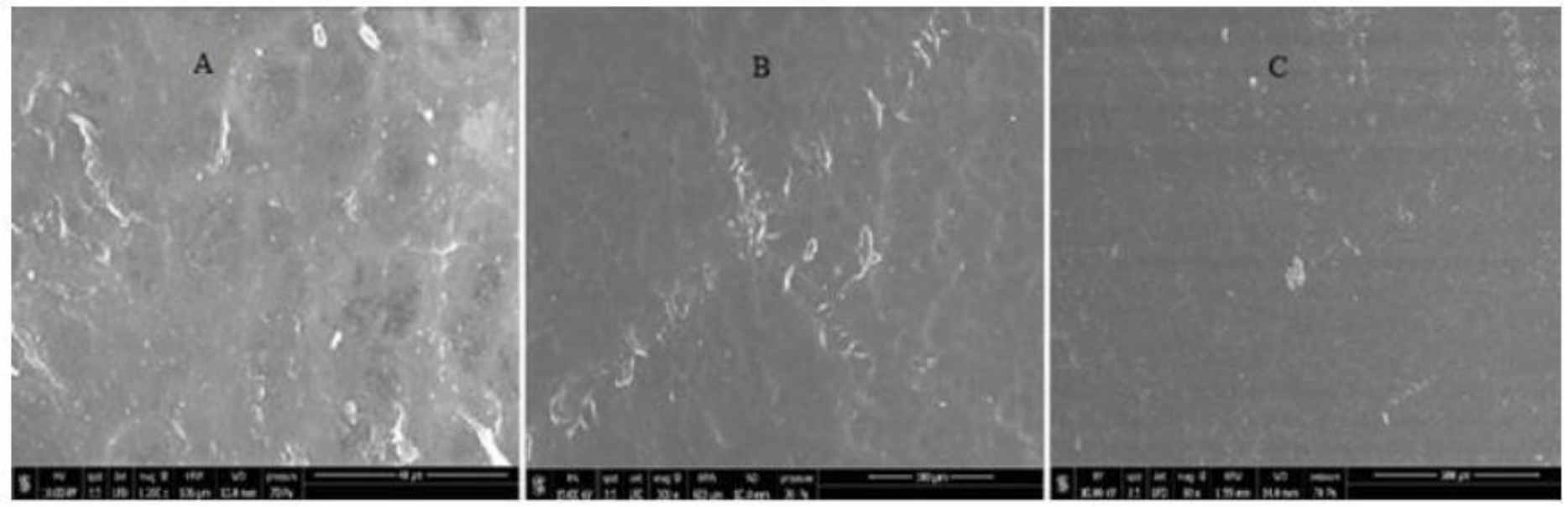

\section{Figure 3}

SEM micrograph of Rsd ( pet-Al) ; (A) : without reagent, (B) : in the presence of $\mathrm{NaOH},(C)$ : in the presence of $\mathrm{KOH}$
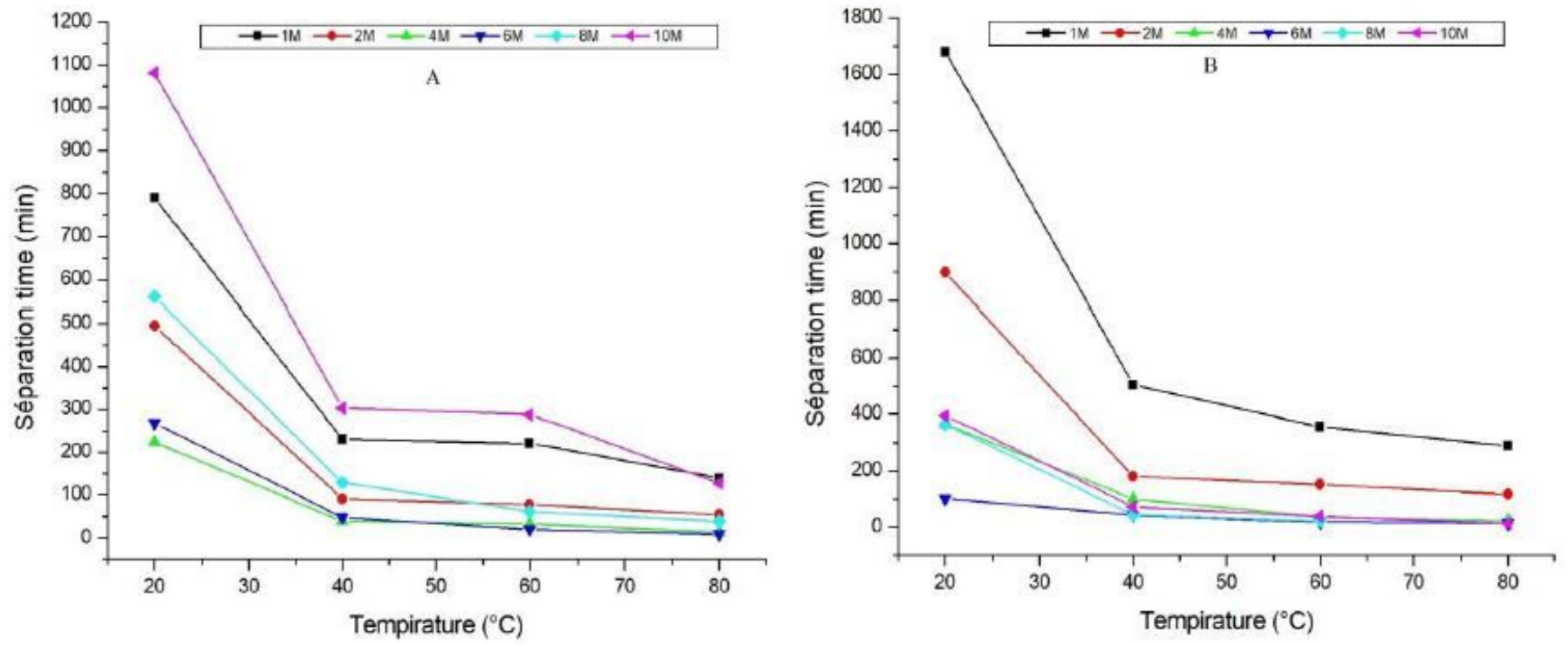

\section{Figure 4}

The separation kinetics by, (A) : $\mathrm{NaOH}$ and (B) : $\mathrm{KOH}$ 


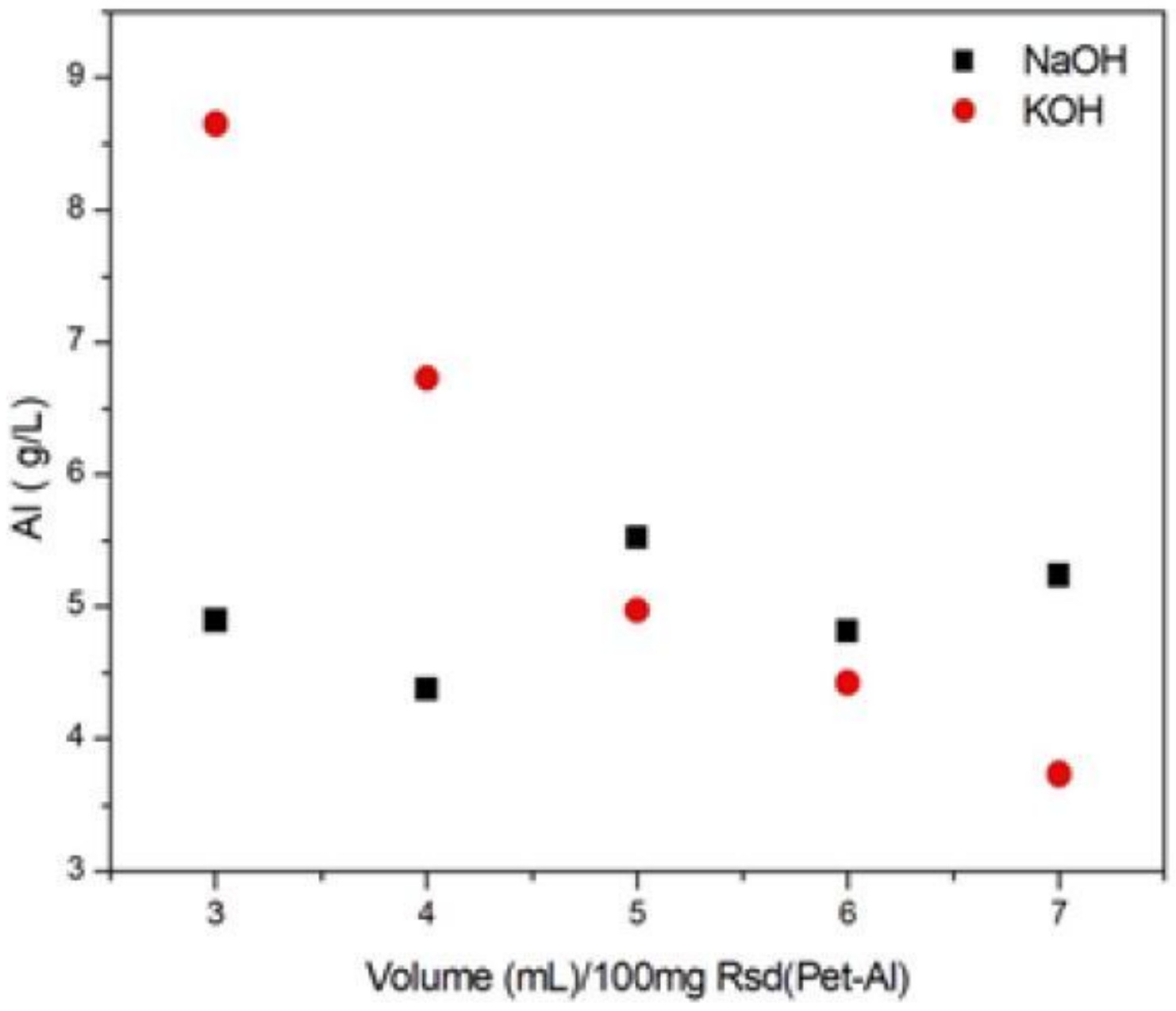

Figure 5

Liquid / solid ratio 


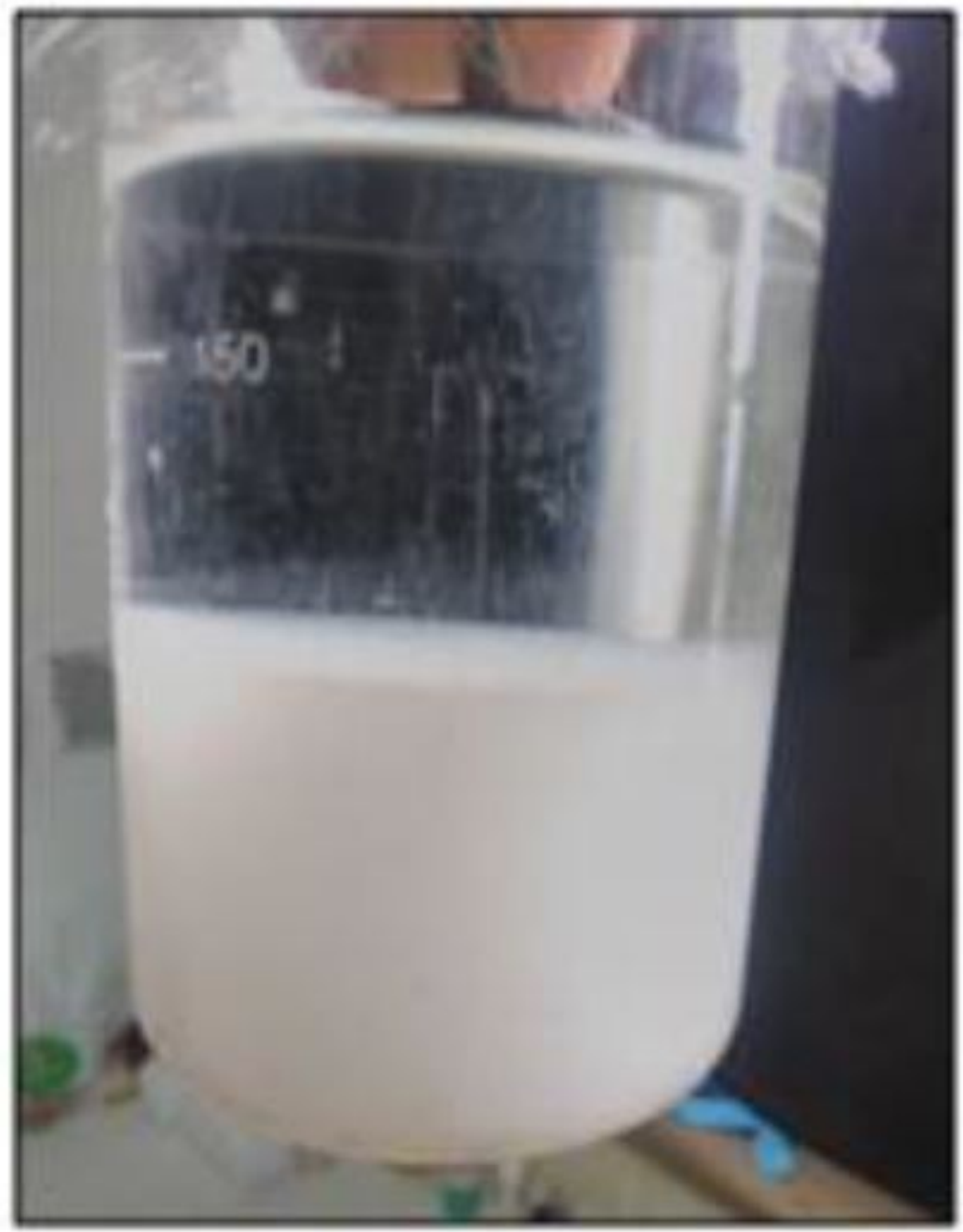

Figure 6

Residue solution after addition of $1 \mathrm{M}$ of $\mathrm{HCl}$
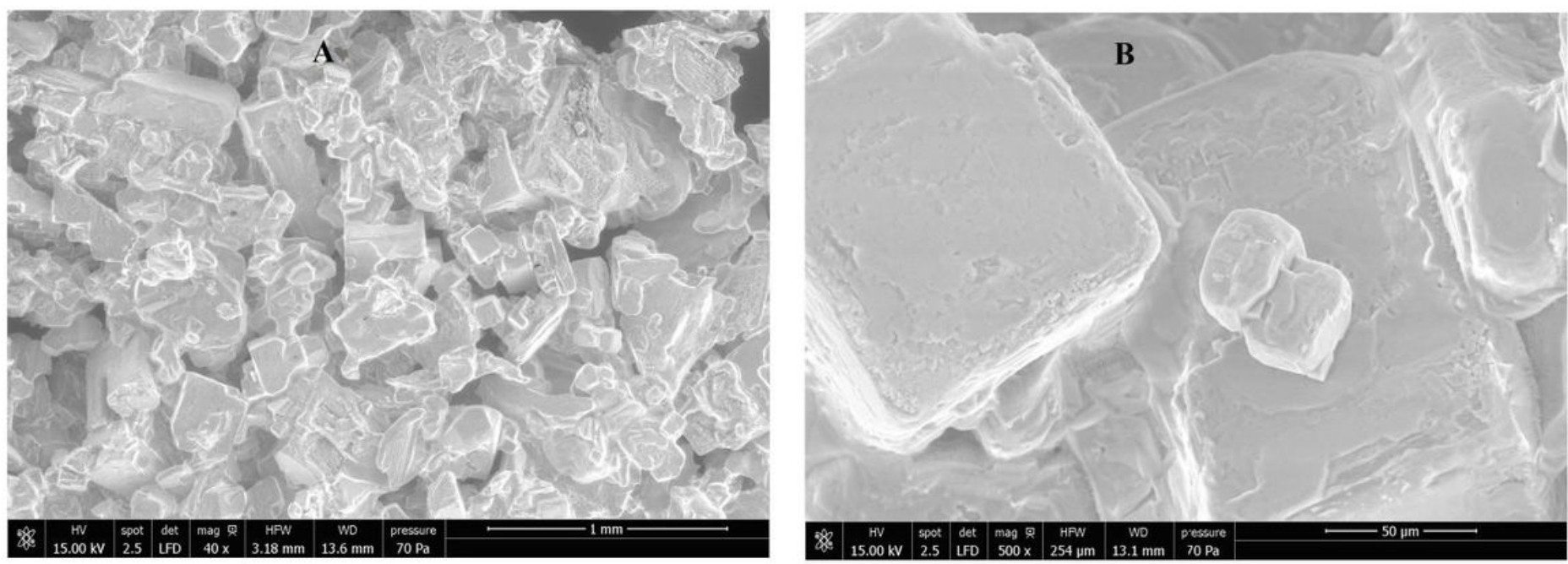
Figure 7

The SD2 micrograph for an enlargement of $1 \mathrm{~mm}(A)$, then $50 \mu \mathrm{m}(B)$

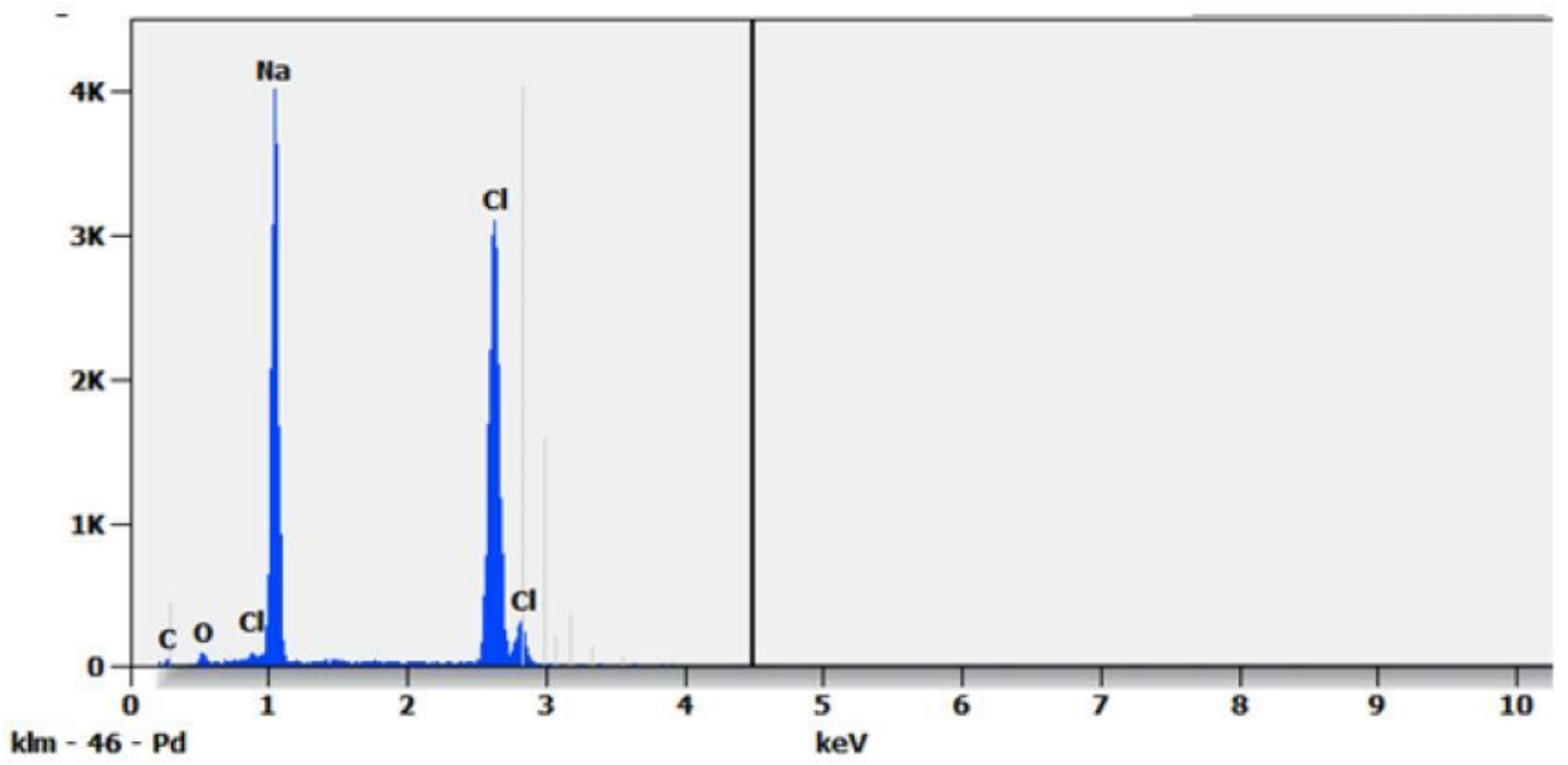

Figure 8

The SD2 SEM spectrum 


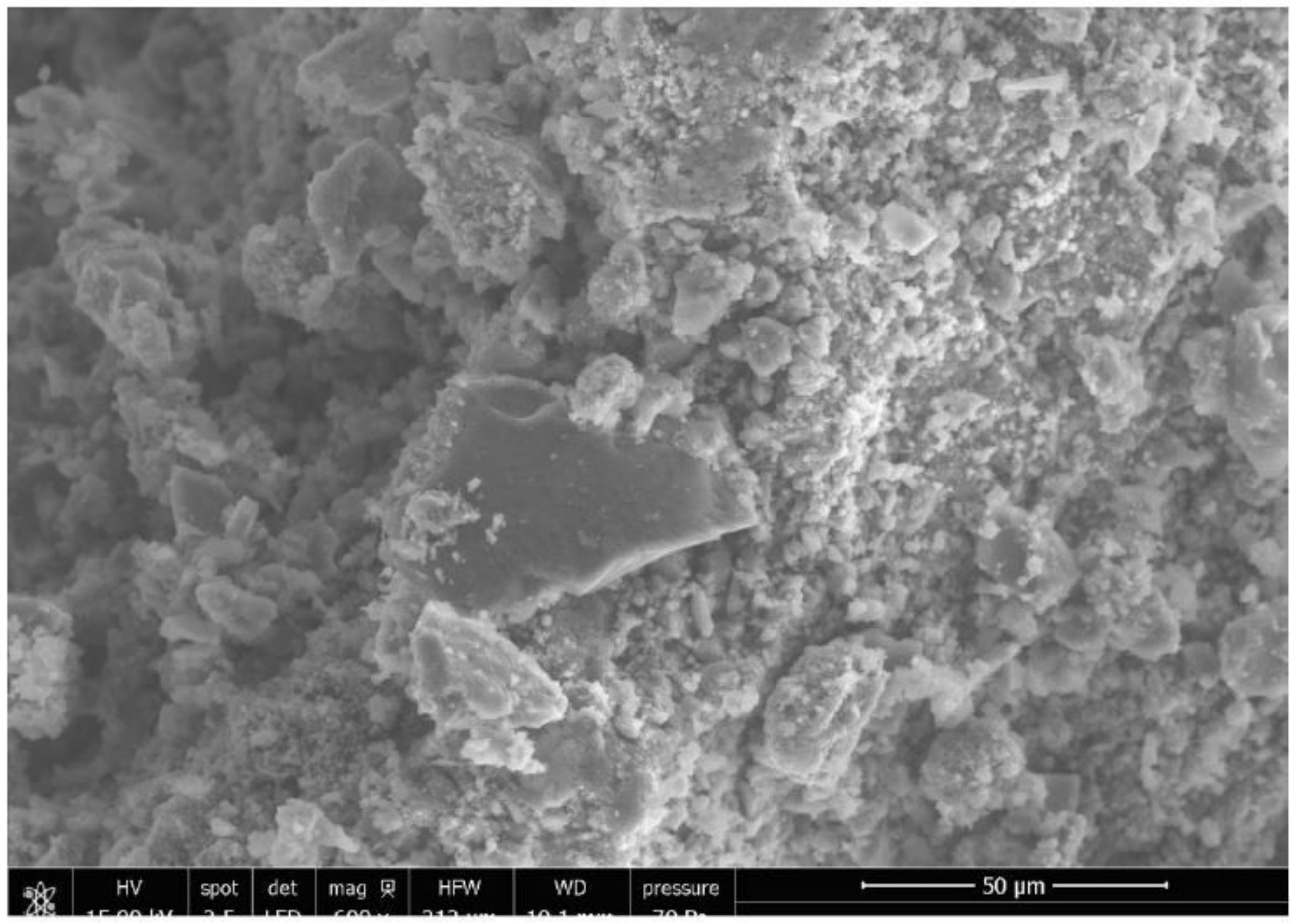

Figure 9

The SD3 micrograph for an enlargement of $50 \mu \mathrm{m}$ 


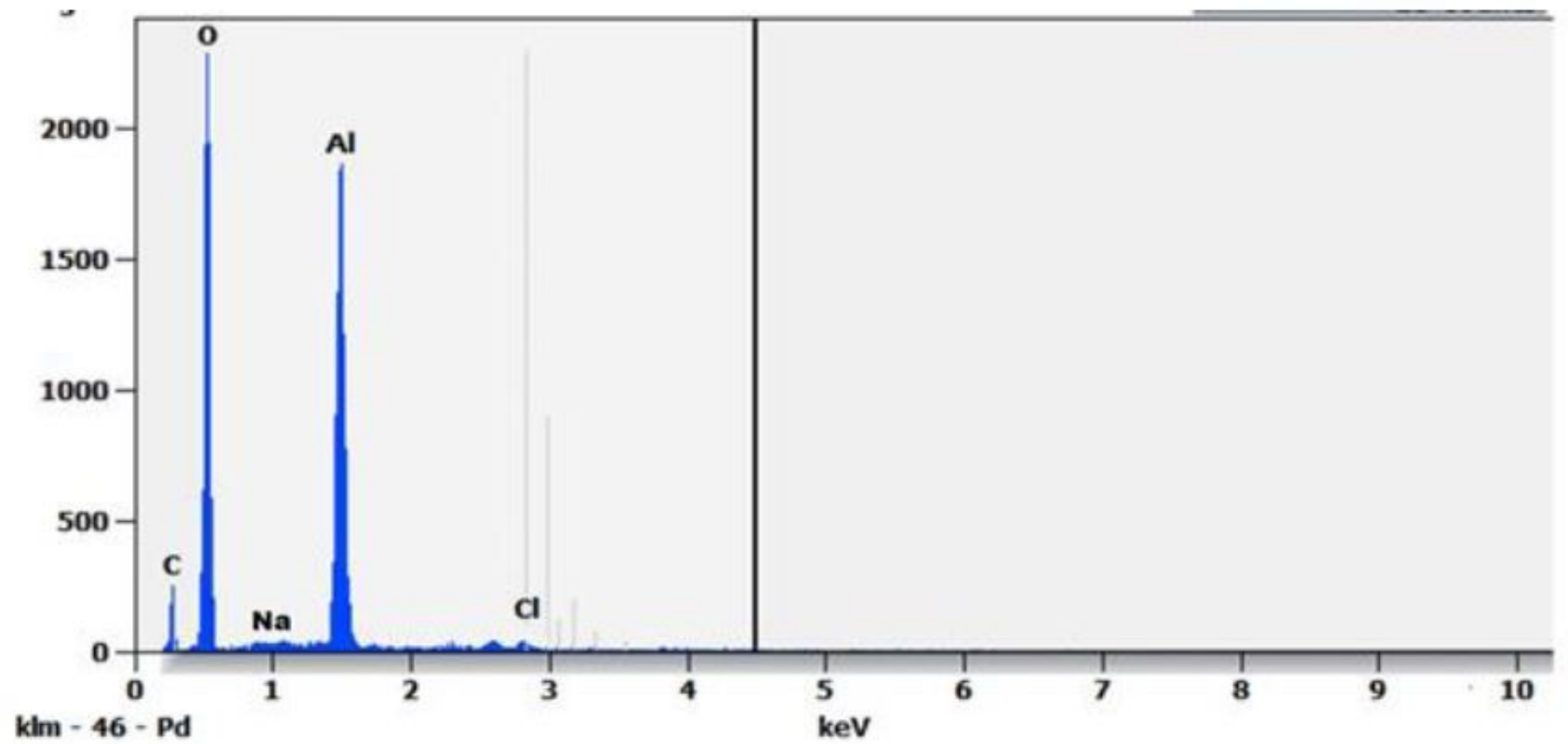

Figure 10

The SD3 SEM spectrum 


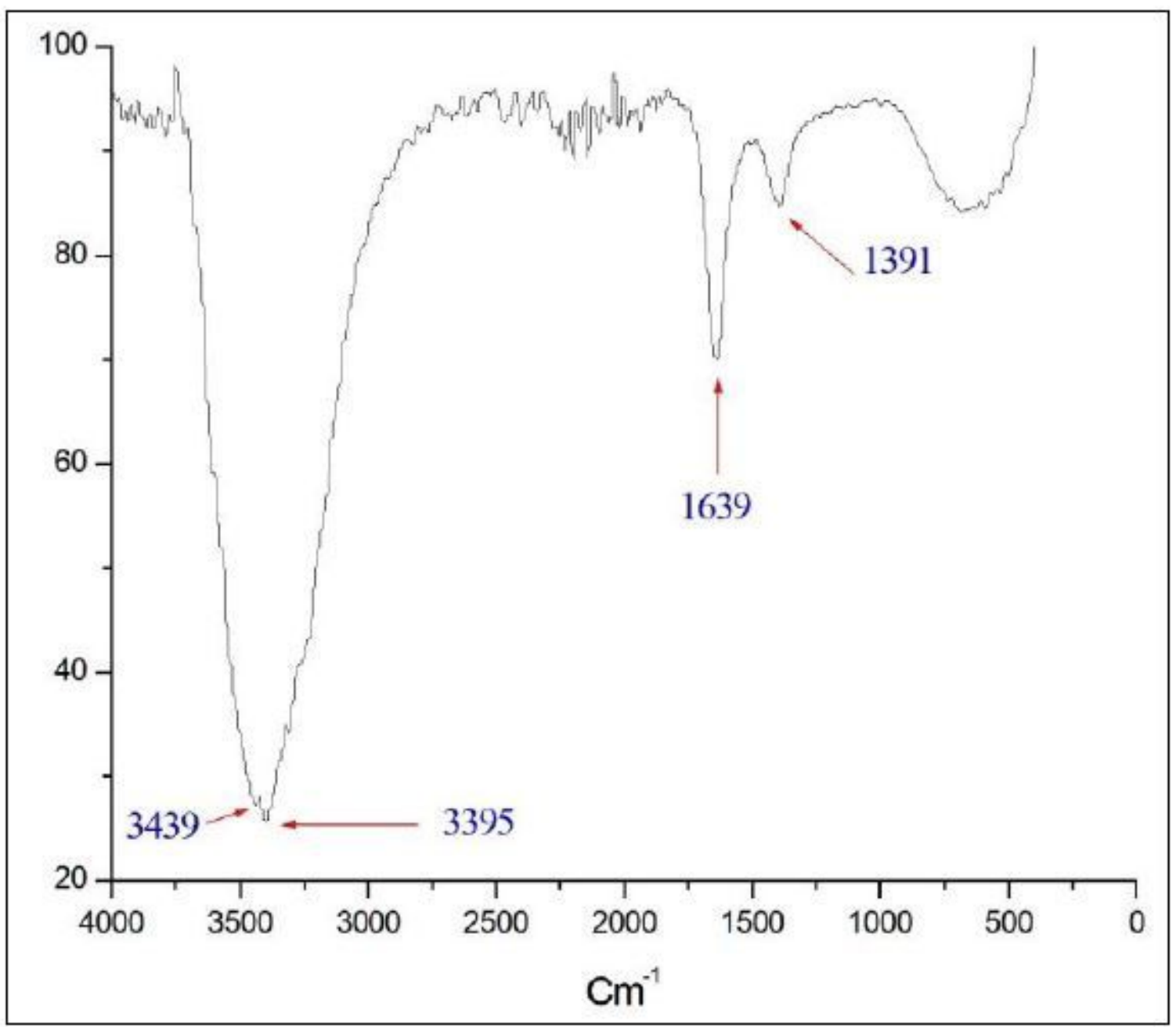

Figure 11

IR spectrum of solid SD2 


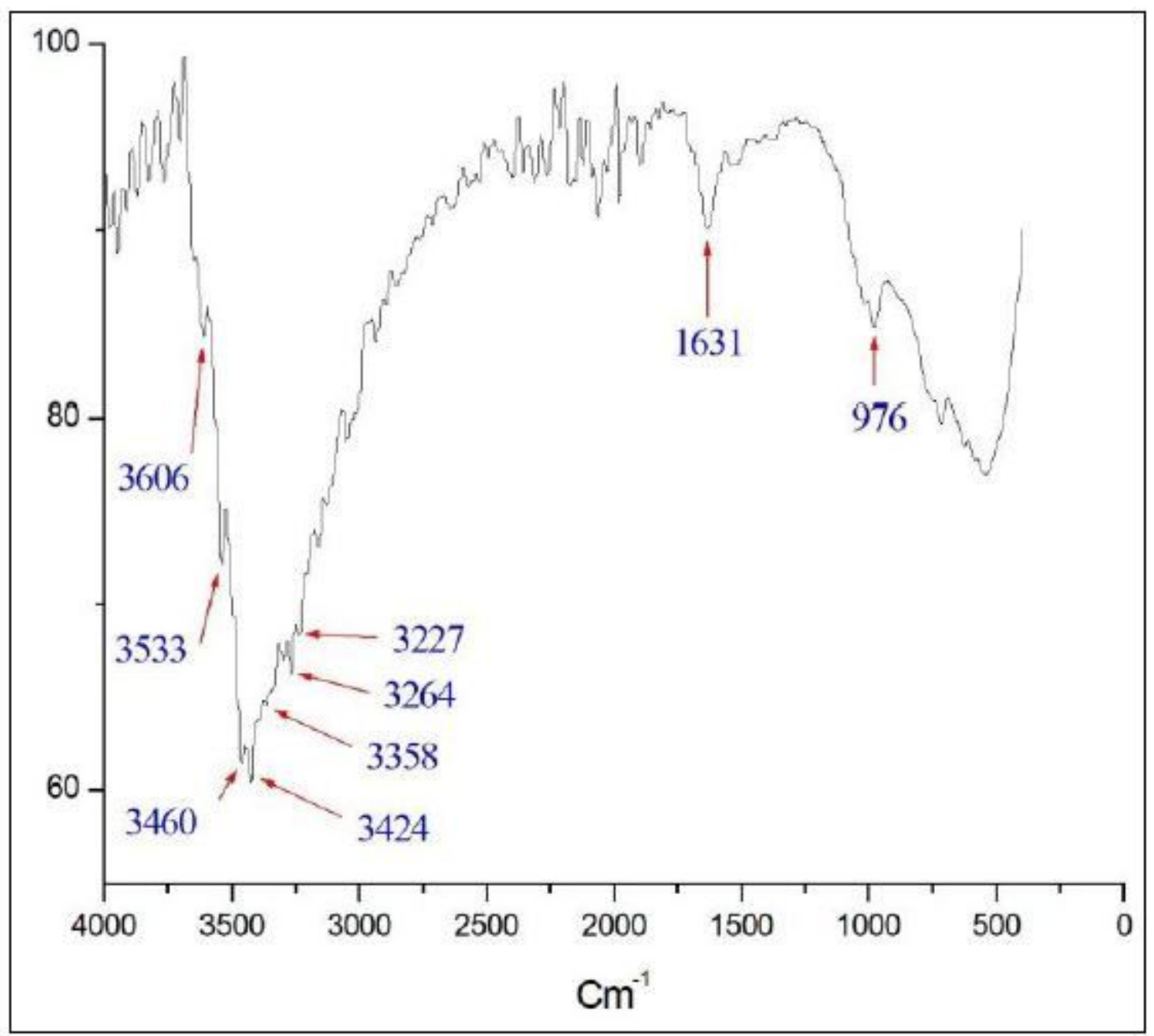

Figure 12

IR spectrum of solid SD3 


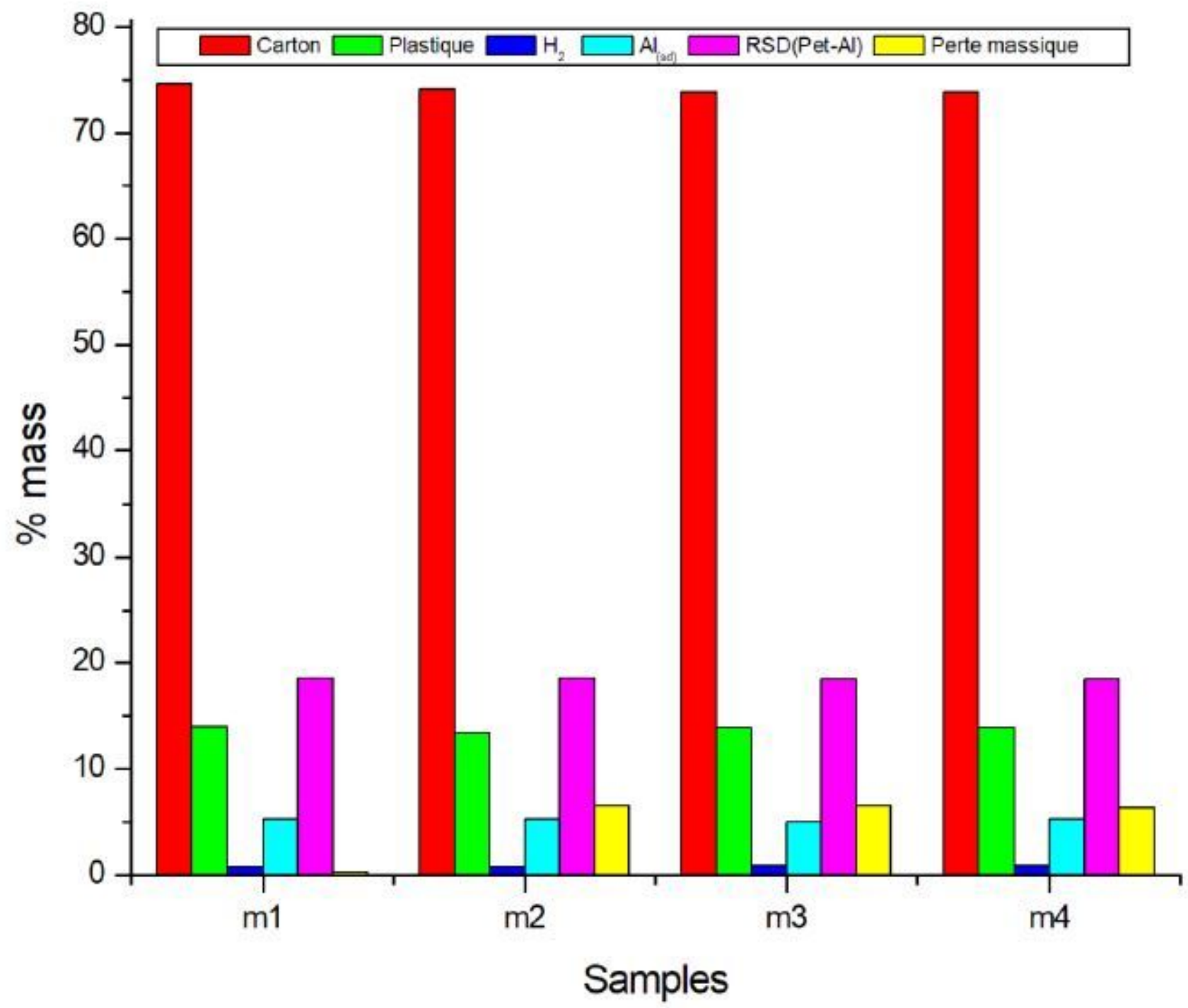

Figure 13

The $\%$ mass evolution of the samples 


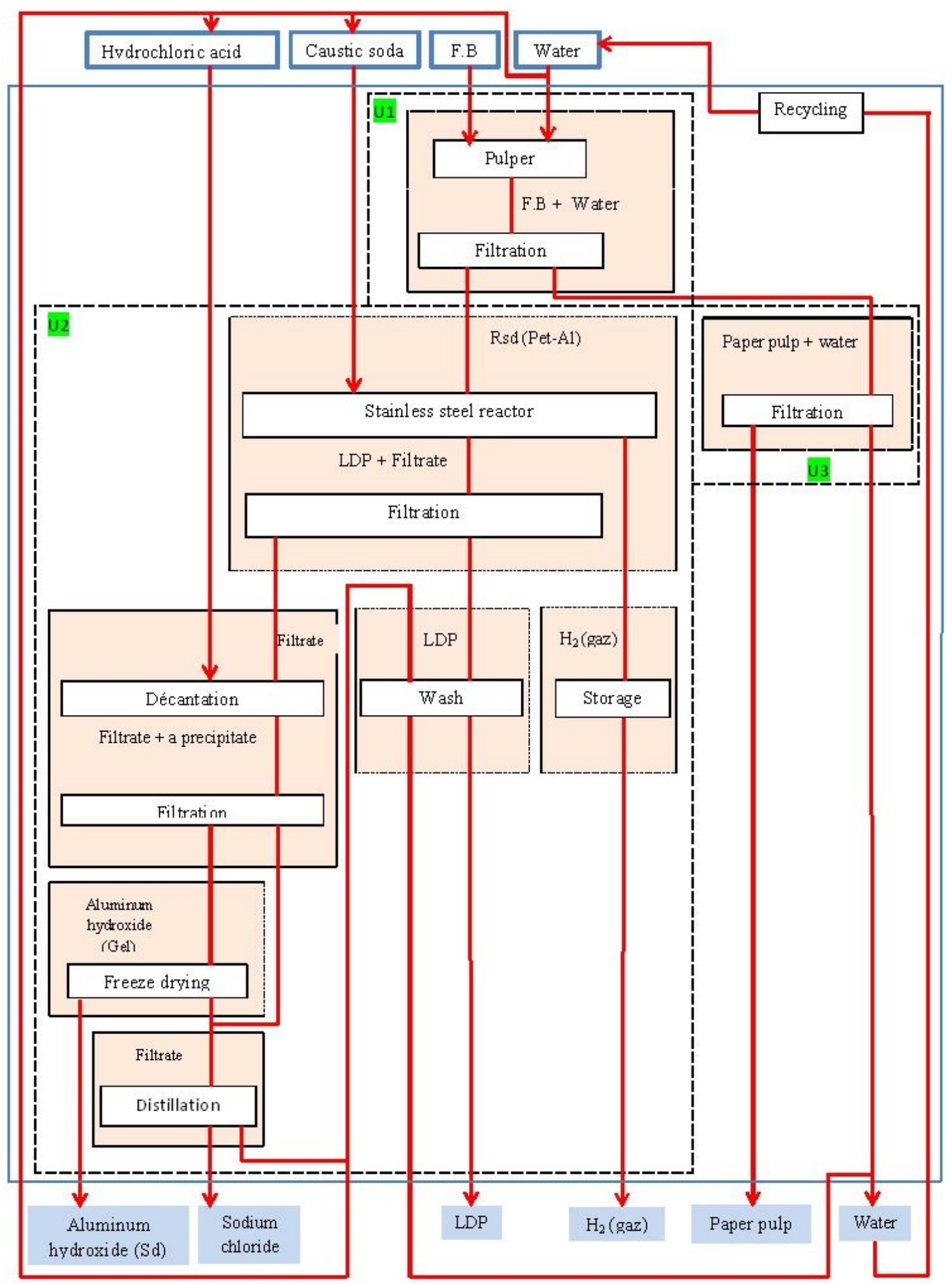

Figure 14

Flow chart of the industrial continuous separation process

\section{Supplementary Files}

This is a list of supplementary files associated with this preprint. Click to download. 
- ga.jpg

- tables1.pdf 